\title{
Antioxidant Potential of Selected Korean Edible Plant Extracts
}

\author{
Yaejin Woo, ${ }^{1}$ Hyeji Lee, ${ }^{2}$ Yong-Seob Jeong, ${ }^{2}$ Ga Young Shin, ${ }^{1}$ \\ Ja Gyeong Oh, ${ }^{1}$ Jong-Sang Kim, ${ }^{1}$ and Jisun $\mathrm{Oh}^{1}$ \\ ${ }^{1}$ School of Food Science and Biotechnology, Kyungpook National University, Daegu 41566, Republic of Korea \\ ${ }^{2}$ Department of Food Science and Technology, Chonbuk National University, Jeonju 54896, Republic of Korea
}

Correspondence should be addressed to Jong-Sang Kim; vision@knu.ac.kr and Jisun Oh; j.oh@knu.ac.kr

Yaejin Woo and Hyeji Lee contributed equally to this work.

Received 8 May 2017; Revised 20 September 2017; Accepted 24 September 2017; Published 6 November 2017

Academic Editor: Pierluigi Di Ciccio

Copyright (C) 2017 Yaejin Woo et al. This is an open access article distributed under the Creative Commons Attribution License, which permits unrestricted use, distribution, and reproduction in any medium, provided the original work is properly cited.

\begin{abstract}
This study aimed to evaluate the antioxidant activity of various plant extracts. A total of 94 kinds of edible plant extracts obtained from the Korea Plant Extract Bank were screened for cytotoxicity, following which the total phenolic content of 24 shortlisted extracts was determined. Of these, extracts from three plants, namely, Castanea crenata (CC) leaf, Camellia japonica (CJ) fruit, and Viburnum dilatatum (VD) leaf, were examined for antioxidant capabilities by measuring radical scavenging activity, ferric reducing/antioxidant power, and lipid peroxidation inhibitory activity. In addition, cellular antioxidant activities of the three extracts were assessed by a cell-based dichlorofluorescein assay and antioxidant response element (ARE) reporter activity assay. The results demonstrated that all three extracts concentration-dependently scavenged free radicals, inhibited lipid peroxidation, reduced the cellular level of reactive oxygen species, and increased ARE-luciferase activity, indicating antioxidant enzyme-inducing potential. In particular, CJ extract showed significantly greater antioxidative activity and antimigratory effect in a breast cancer cell line compared to CC and VD extracts. Hence, CJ extract deserves further study for its in vivo functionality or biologically active constituents.
\end{abstract}

\section{Introduction}

Oxidative stress caused by free radicals and their derivatives leads to disturbances in redox homeostasis [1]. Reactive oxygen species (ROS) are endogenously produced during intracellular metabolic processes but can also be generated by exogenous stimuli such as UV radiation, pollutants, smoke, and drugs $[2,3]$. When intracellular oxidative status increases, the cell triggers its defense systems or undergoes apoptosis [2]. These responses to oxidative stress influence numerous cellular processes including core signaling pathways, which are associated with development of systematic and/or chronic disorders including aging and cancer $[3,4]$. Therefore, it is critical to remove cellular oxidants and restore redox balance.

Edible plants or plant-derived compounds can be used medicinally as preventive and/or therapeutic measures against a variety of disorders [5]. A number of studies attribute health benefits of dietary plants to biologically active constituents that possess strong antioxidant activity [6]. This has resulted in extensive studies on plant extracts or constituents that are capable of scavenging free radicals and inhibiting lipid peroxidation $[7,8]$.

It has been well established that the antioxidant capacity of plant extracts is closely associated with their total phenolic content. Furthermore, some antioxidants are known to activate cellular antioxidant defense systems $[9,10]$. The nuclear factor erythroid 2- (NFE2-) related factor 2 (Nrf2), a transcription factor, is known to be a master regulator of the cellular antioxidant response. This has given rise to the strategy of searching for substances inducing Nrf2 activation in development of functional foods or nutraceuticals $[1,9]$.

In the present study, we screened 94 edible plant extracts for cytotoxicity and chose 24 of these for measurement of total phenolic contents. In addition, we tested antioxidant activity, performed antioxidant response element (ARE) reporter assays for three selected plant extracts, and examined their antimigratory effects in a human breast cancer cell line, MCF-7. 


\section{Materials and Methods}

2.1. Preparation of Plant Extracts. A total of 94 edible plant extracts were purchased from the Korea Plant Extract Bank (Ochang, Chungbuk, Korea) [11]. According to the supplier, each plant material was washed, air-dried at $70^{\circ} \mathrm{C}$, ground, and extracted in $100 \%$ methanol at $30^{\circ} \mathrm{C}$ for 3 days. The extract solution was then filtered and vacuum-evaporated to dryness. For in vitro measurement of antioxidant activity, the obtained extracts were dissolved in dimethyl sulfoxide (DMSO; Sigma-Aldrich, St. Louis, MO, USA) at $20 \mathrm{mg} / \mathrm{mL}$.

2.2. Determination of Total Phenolic Contents. The total phenolic contents of the extracts were measured as described by Ariffin and coworkers [12, 13] with minor modifications [13], using a high-performance liquid chromatography system equipped with a diode array detection module (HPLC-DAD; Waters Corp., Milford, MA).

2.3. Determination of Cytotoxicity. To test the cytotoxicity of each extract, Cell Counting Kit-8 (CCK-8; Dojindo Laboratories, Kumamoto, Japan) was used as previously described [14]. Cytotoxicity of each extract was expressed as an $\mathrm{IC}_{50}$ value that indicates the concentration of the extract at which cell viability is reduced by $50 \%$ in comparison to the control treatment. The $\mathrm{IC}_{50}$ values were obtained by nonlinear regression using GraphPad Prism (ver. 3.0).

2.4. Determination of Free Radical Scavenging Capacity. Antioxidant activity of the extracts was assessed by the ability to scavenge 2,2-diphenyl-1-picrylhydrazyl (DPPH) or 3-ethylbenzothiazoline-6-sulfonic acid (ABTS) radicals as previously described [15]. Butylated hydroxytoluene (BHT), a synthetic antioxidant, or $\alpha$-tocopherol was used as a positive control for both assays.

2.5. Determination of Ferric Reducing/Antioxidant Power (FRAP). The FRAP assay was performed as previously described $[16,17]$. $\alpha$-Tocopherol was used as a positive control at concentrations of $50,100,500$, and $1,000 \mu \mathrm{M}$ in comparison to the negative control (a solvent-treated condition).

2.6. Measurement of Lipid Peroxidation Inhibition. The supernatant of mouse liver homogenate was used for thiobarbituric acid reactive substances (TBARS) assay measuring the level of an end-product of lipid peroxidation, malondialdehyde (MDA) [17]. After various concentrations of samples or positive control BHT were mixed with the liver homogenate, peroxidation was induced using $20 \mathrm{mM}$ ferric chloride. The absorbance of the reactant was measured at $532 \mathrm{~nm}$. The lipid peroxidation inhibitory activity of a sample was calculated.

2.7. Cell Culture. The human breast cancer cell line MCF7 , used for the cytotoxicity assay, was obtained from the Korean Cell Line Bank (KCLB, Seoul, Korea) and maintained in Dulbecco's modified Eagle's medium (DMEM) supplemented with $10 \%$ fetal bovine serum (FBS) and $1 \%$ penicillinstreptomycin (all from Invitrogen, Carlsbad, CA, USA).

A human hepatoma cell line HepG2, obtained from KCLB, was transfected with pGL4.37[luc2P/ARE/Hygro] vector (Promega, Madison, WI, USA) as previously described [18]. The transfectant carrying an ARE-luciferase construct was named HepG2-ARE and cultured in the maintenance medium including $0.4 \mathrm{mM}$ hygromycin (Sigma-Aldrich). All cultures were kept in a culture incubator $\left(37^{\circ} \mathrm{C}, 5 \% \mathrm{CO}_{2}\right.$, humidified) for the designated period.

2.8. Quantification of Cellular Oxidative Stress: Dichlorofluorescein (DCF) Assay. The intracellular reactive oxygen species (ROS) concentration was quantified by measuring the oxidation level of 2,7-dichlorodihydrofluorescein diacetate (DCFH-DA; Sigma-Aldrich) as described by Wang and Joseph [19]. MCF-7 cells were treated with samples at designated concentrations in $0.5 \%$ FBS-containing culture medium for $24 \mathrm{~h}$. ROS production was induced by $100 \mu \mathrm{M}$ tert-butyl hydroperoxide (tBHP), an oxidant, for $4 \mathrm{~h}$ before termination of sample treatment. The cells were then treated with $50 \mu \mathrm{M}$ DCFH-DA for $1 \mathrm{~h}$ at $37^{\circ} \mathrm{C}$. After removal of the excess DCFH-DA, fluorescence was measured using a microplate reader at excitation and emission wavelengths of 485 and $535 \mathrm{~nm}$.

2.9. Measurement of Antioxidant Response Element (ARE) Activity Assay. Luciferase reporter assay was conducted on HepG2-ARE cells as described [18, 20]. The cells were treated with samples for $12 \mathrm{~h}$ after serum starvation (0.5\% FBS, $12 \mathrm{~h})$. The luciferase activity, which corresponded to the ARE activity, was measured using a luciferase assay system (Promega) according to the manufacturer's instruction. Sulforaphane (Sigma-Aldrich), an isothiocyanate, was used as an ARE activator. Brusatol (Carbosynth Ltd., Newbury, Berkshire, UK), a quassinoid, was used as a specific inhibitor of the Nrf2 pathway [21]. The luminescence of the assay was detected and calibrated on total protein amounts. The data were then normalized against the control values.

2.10. Cell Cycle Analysis. To determine the proliferative capacity of cultured cells, 5-ethynyl-2' -deoxyuridine (EdU) uptake analysis was performed using Click-iT ${ }^{\circledR}$ EdU flow cytometry assay kit (Life Technologies). For the assay, cells were prepared as recommended by the manufacturer's instruction. Briefly, cells were cultured for $48 \mathrm{~h}$ and subsequently treated with $10 \mu \mathrm{M}$ EdU for $2 \mathrm{~h}$, harvested, and washed in phosphate-buffered saline (PBS; Gibco) containing $1 \%$ bovine serum albumin (BSA; Sigma-Aldrich). After fixation and permeabilization, EdU-incorporation was visualized in Click-iT reaction cocktail containing Alexa Flour ${ }^{\circledR} 488$ azide. After being rinsed, $1 \times 10^{4}$ cells per condition were analyzed by the BD FACSCalibur flow cytometer (BD Biosciences).

2.11. Cell Migration Assay. For measurement of in vitro cell migration [22], MCF-7 cells were plated onto a 6-well plate coated with $10 \mu \mathrm{g} / \mathrm{mL}$ of poly-L-ornithine (Sigma-Aldrich) and $5 \mu \mathrm{g} / \mathrm{mL}$ of human plasma fibronectin (Life Technologies) at a density of $1 \times 10^{5}$ cells per well. At about $90 \%$ confluence in the growth medium (DMEM containing $10 \%$ FBS), an artificial gap was created on a cell monolayer by scraping the cells in a straight line with a P200 pipet tip. 
After removing the detached cells, the growth medium was replaced with $2 \%$ FBS-containing medium for the designated period in the absence or presence of phorbol ester (12$O$-tetradecanoylphorbol-13-acetate; TPA), an enhancer of cell motility $[23,24]$. Culture images were captured at the beginning and every $24 \mathrm{~h}$ for the designated period using an optimal microscope (Labomed TCM 400, Labo America, Inc., Fremont, CA, USA, photographed by Eyecam, Bimeince, Suwon, Korea). The migration rate was calculated as follows: migration rate $(\%)=[($ width at $0 \mathrm{~h}-$ width at $24 \mathrm{~h}) /$ width at $0 \mathrm{~h}] \times 100$.

2.12. Statistical Analysis. The obtained data were analyzed by one-way analysis of variance and Duncan's multiple range test using the SPSS statistics 22 software (SPSS Inc., Chicago, IL, USA). Comparisons between two groups were performed by Student's unpaired $t$-test, and $p$ values less than 0.05 were considered significant. Statistical differences were indicated with asterisks, hashtags, or different alphabetical letters.

\section{Results and Discussion}

A total of 94 plant extracts were screened for cytotoxicity (partially shown in Table 1) and a selection of them were tested for total phenolic content. Cytotoxicity was assessed based on MCF-7 cell viability at various concentrations of each extract and expressed as $\mathrm{IC}_{50}$ values. According to the screening program of the National Cancer Institute, USA, a plant extract is generally considered actively cytotoxic if the $\mathrm{IC}_{50}$ value is $\leq 20 \mu \mathrm{g} / \mathrm{mL}[25,26]$. As the $\mathrm{IC}_{50}$ values of all sample extracts tested in the study were higher than $20 \mu \mathrm{g} / \mathrm{mL}$, the test samples could be considered not actively cytotoxic. To maximize the probability of antioxidant activity expression and ensure the nontoxicity of the test samples, extracts with $\mathrm{IC}_{50}$ values in the range of 20 to $200 \mu \mathrm{g} / \mathrm{mL}$ were selected (Table 1). The 24 selected extracts were then analyzed for total phenolic content by HPLC analysis. The extracts from fruits of Camellia japonica (CJ), leaves of Viburnum dilatatum (VD), and leaves of Castanea crenata (CC) showed the highest values for total phenolic content (Table 1) and were therefore subjected to further antioxidant assays.

The antioxidant capabilities of these extracts were evaluated by measurement of radical scavenging activity, FRAP assay, and lipid peroxidation inhibition testing (Figure 1). All three kinds of extracts induced an increase in radical scavenging activity and FRAP values in a concentration-dependent manner (Figures 1(a)-1(c)). In particular, the scavenging activity and FRAP values of CJ extract were significantly greater than those of VD or CC extracts at concentrations $\geq$ $25 \mu \mathrm{g} / \mathrm{mL}$. In addition, lipid peroxidation inhibitory activity was determined via measurement of MDA levels using mouse liver tissue homogenate treated with various concentrations of the extracts (Figure $1(\mathrm{~d})$ ). The concentration-dependent decrease in MDA levels observed was consistent with radical scavenging activities of the extracts. These results demonstrated that $\mathrm{CC}, \mathrm{CJ}$, and $\mathrm{VD}$ extracts have relatively strong antioxidant capabilities.

To examine whether these extracts can protect mammalian cells from oxidative stress, cultures of a human mammary gland-derived epithelial cell line MCF-7 were treated with each extract prior to challenging them with tBHP. The intracellular ROS production was determined by the relative intensity of DCF fluorescence (Figure 2(a)). While intracellular ROS formation was significantly promoted by tBHP treatment, the augmented ROS level was significantly lowered by treatment with CC, CJ, or VD extracts. This finding is indicative of the antioxidative capability of the three sample extracts in a living cell model as well as in an in vitro system.

To elucidate the potential mechanism by which these extracts exert antioxidant activity, ARE-luciferase activity was measured in HepG2-ARE cells following extract treatment (Figure 2(b)). As expected, ARE-luciferase activity was significantly increased by sulforaphane, a known Nrf2 activator, and suppressed by simultaneous treatment with brusatol, an Nrf2 inhibitor. All three sample extracts were found to induce ARE activation, which was partially or completely abolished by brusatol. However, CC-induced ARE activation was not influenced by brusatol. These results suggest that the antioxidative function of CJ and VD extracts was, at least in part, mediated via the Nrf2 signaling pathway. Moreover, our previous data demonstrated that CC itself did not increase the levels of Nrf2 or its downstream gene transcripts in MCF-7 cells [18]. Considering that brusatol reversibly enhances ubiquitination and degradation of Nrf2 [21], CC-induced ARE activation, which is unaffected by brusatol, may be accomplished by different mechanism(s) from the other samples. For instance, CC may activate the Nrf2 signaling pathway through the modulation of PI3K and/or MAPK instead of directly interacting with Keap1 protein, which is present in the form of a heterodimer with Nrf2 in the cytoplasm [27-29]. However, the precise molecular mechanisms for the antioxidative function of CC extract must be revealed through further study.

Since Nrf2-mediated redox control is highly correlated with cancer cell proliferation [30,31], we further examined whether those extracts influence cell cycle progression of cancer cells. MCF-7 cells that underwent G1, S, and G2$M$ phases were analyzed by a thymidine analogue, EdUbased cell sorting after treatment with each extract at a concentration of $50 \mu \mathrm{g} / \mathrm{mL}$ for $48 \mathrm{~h}$ (Figure 3(a)). Our data showed that $61.9 \pm 0.1 \%$ of cells were analyzed at G1 phase, $27.4 \pm 0.5 \%$ at $S$ phase, and $8.7 \pm 1.2 \%$ at $\mathrm{G} 2-\mathrm{M}$ phase in the control condition. After exposure to each extract, the cells at G1 phase were slightly decreased and those at S and G2-M phases were marginally increased (data not shown). These findings demonstrate that the three extracts may not significantly influence cell cycle progression of MCF-7 cells at a dose of treatment in this study.

Intriguingly, we found that CJ extract was capable of preventing MCF-7 cell migration in vitro (Figure 3(b)), whereas the other two extracts were not (data not shown). Regardless of the presence of TPA, the migration rate of MCF-7 cells was decreased by treatment with CJ extract at the concentrations of $\geq 50 \mu \mathrm{g} / \mathrm{mL}$. Considering that Nrf2 can promote breast cancer cell migration which is associated with tumor aggressiveness in vivo [32], it is conceivable that CJ 


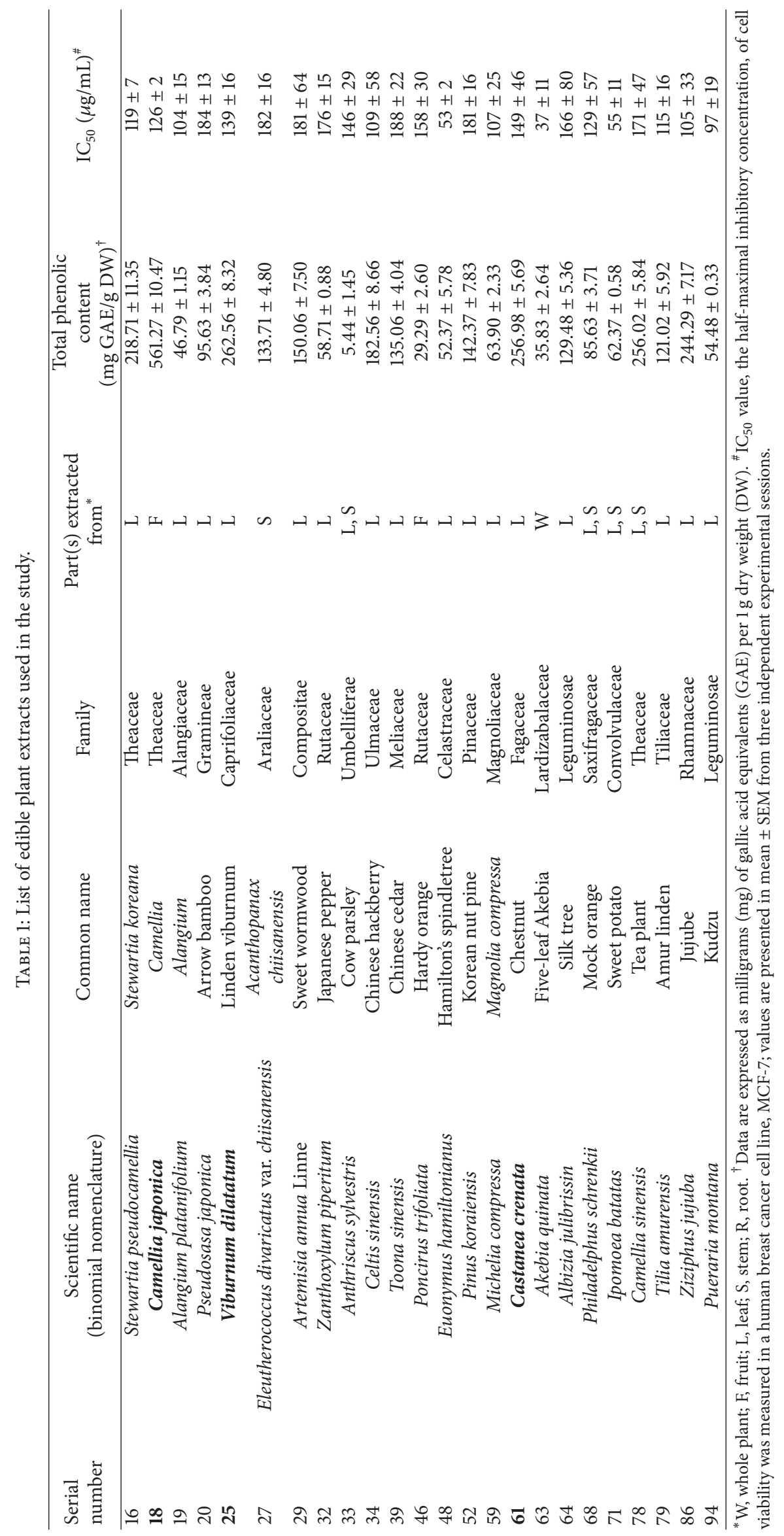



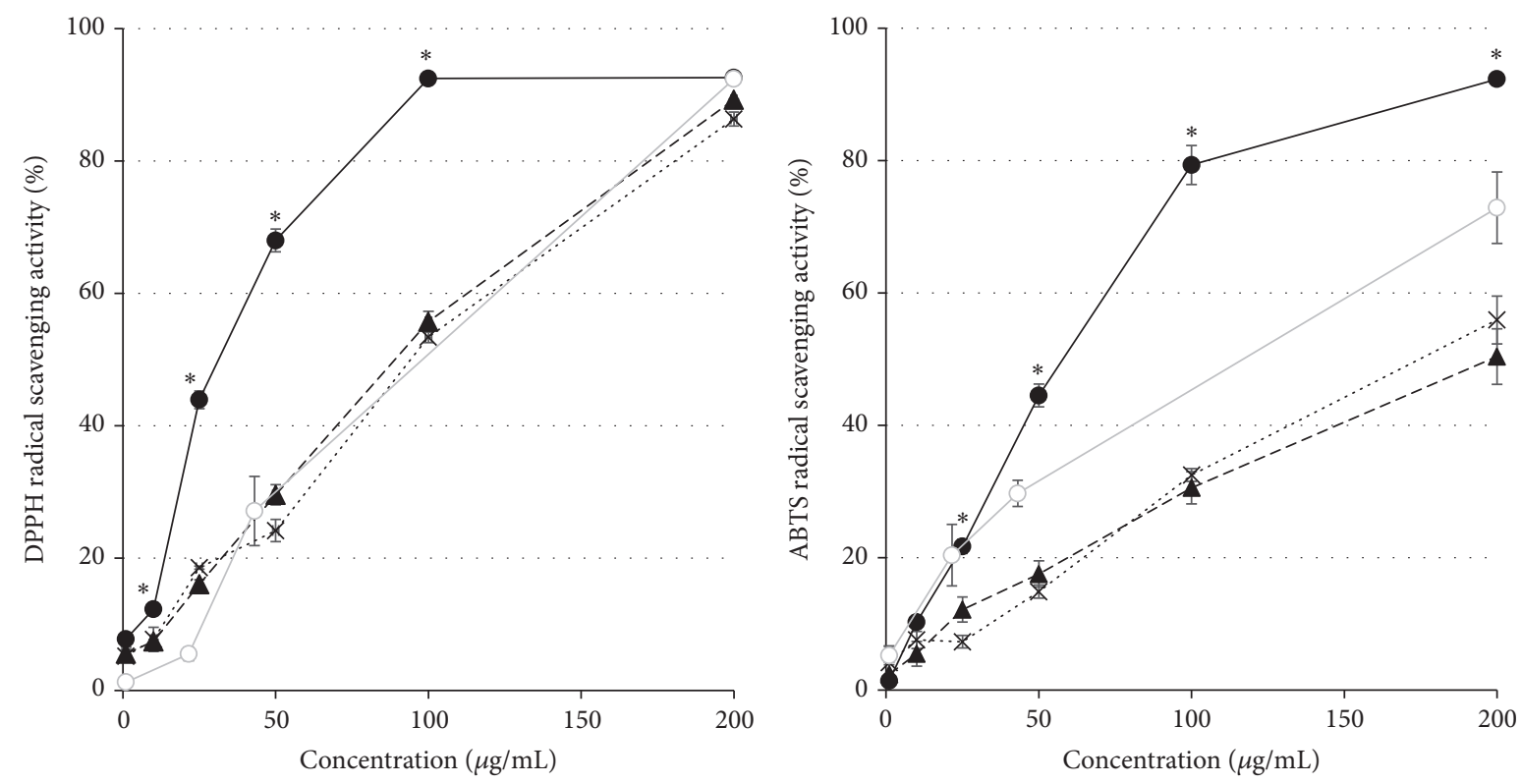

$\cdot \times \cdot$ CC

$\bullet-\mathrm{CJ}$

$-\mathbf{\Delta}-\mathrm{VD}$

$\alpha$-toc

(a)

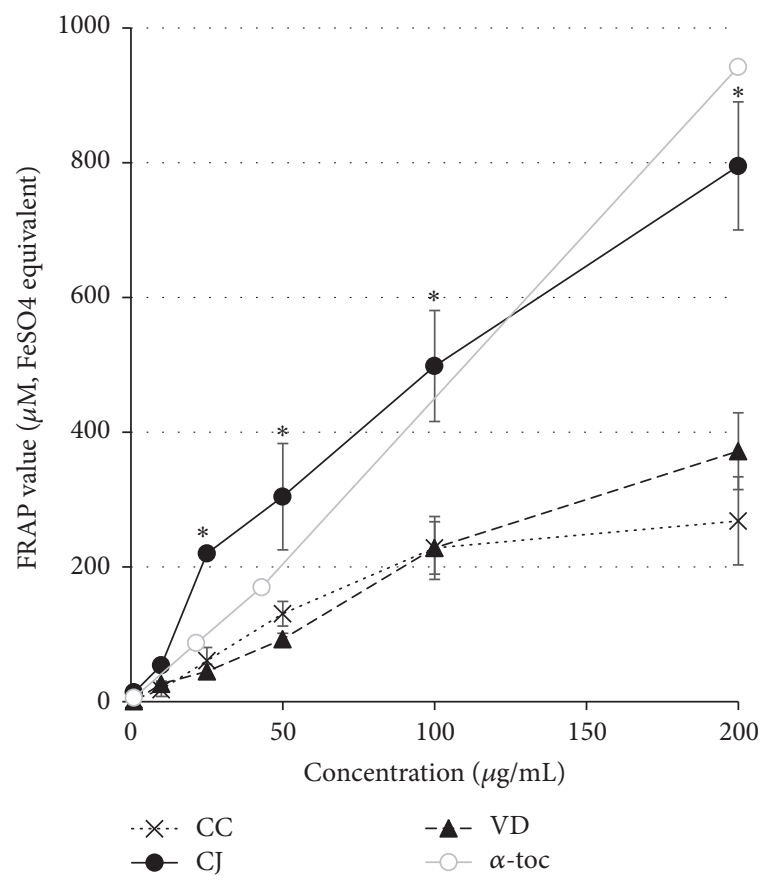

(c)
$-x-\mathrm{CC}$

$-\mathbf{\Delta}-\mathrm{VD}$

(b)

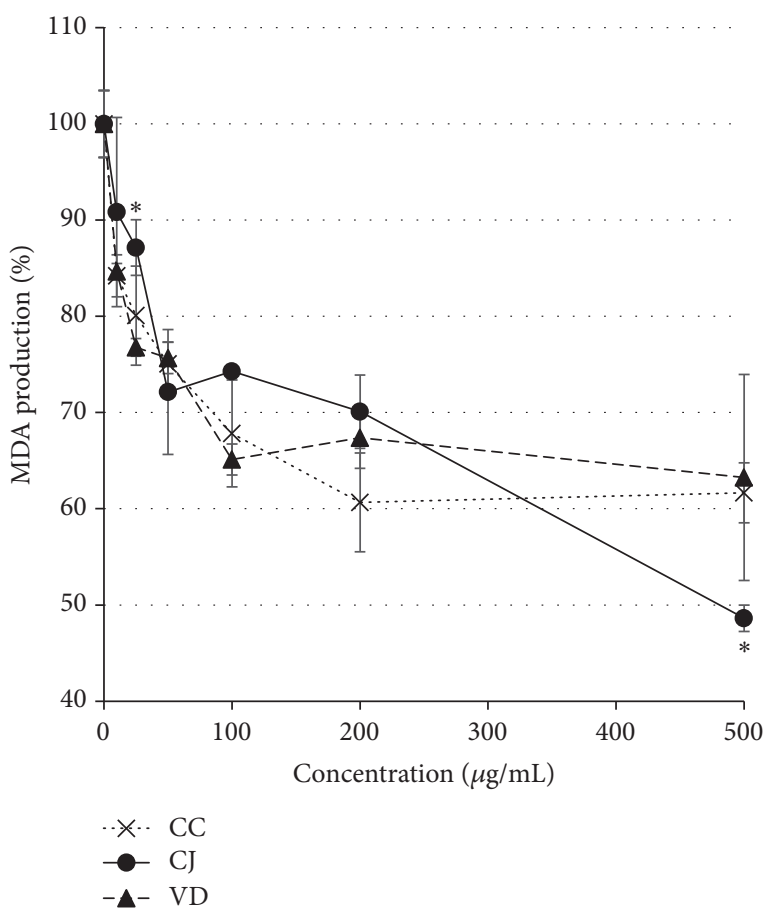

(d)

FIGURE 1: Antioxidant capabilities of CC, CJ, and VD extracts. The three extracts were examined for DPPH radical scavenging activity (a), ABTS radical scavenging activity (b), and FRAP (c) at various concentrations $(1,10,25,50,100$, and $200 \mu \mathrm{g} / \mathrm{mL}$ ). $\alpha$-Toc, $\alpha$-tocopherol, is a positive control. Lipid peroxidation inhibitory activity (d) was measured at 1, 10, 25, 50,100, 200, and 500 $\mu \mathrm{g} / \mathrm{mL}$. $N$ (number of independent experimental sessions) $=3$; error bars, mean \pm SEM. Statistical differences were indicated with asterisks for comparisons between two groups, $\mathrm{CJ}$ and $\mathrm{CC}$ or $\mathrm{VD}$, at the given concentration. 


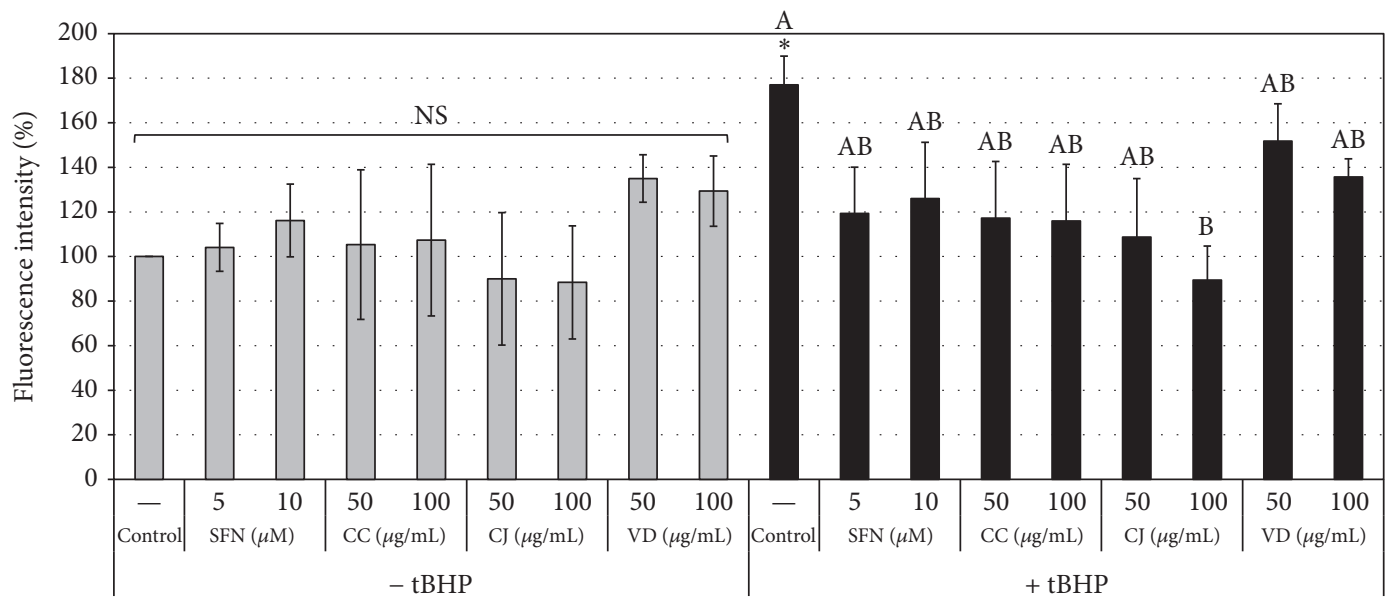

(a)

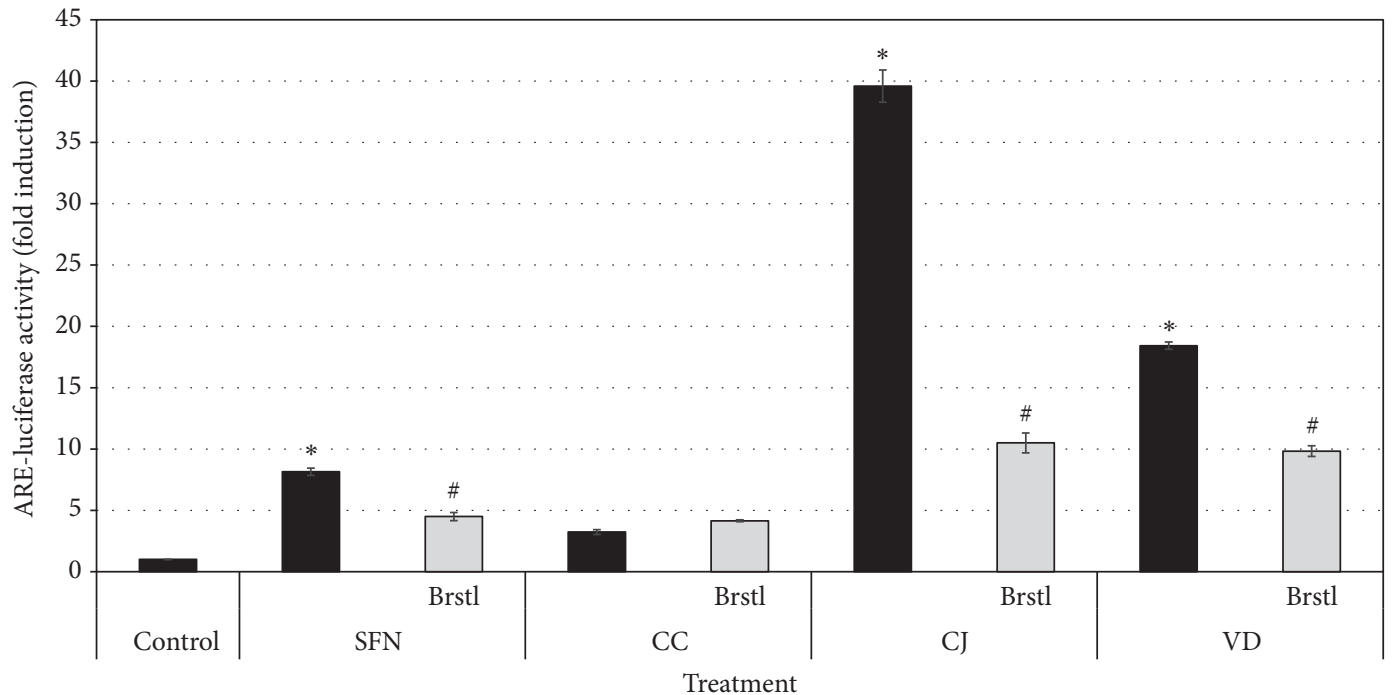

(b)

FIGURE 2: Cellular antioxidant effects of CC, CJ, and VD extracts. (a) MCF-7 cells were treated with the designated extracts and then exposed to tBHP. The intracellular ROS levels were determined by DCF fluorescence intensity. Treatment with CJ extract at $100 \mu \mathrm{g} / \mathrm{mL}$ effectively reduced the tBHP-induced ROS levels. $N=3$; error bars, mean \pm SEM. Asterisk indicates a significant difference in comparison with the control (no tBHP treatment). Different alphabetical letters indicate significant differences among the tBHP-treated conditions. (b) HepG2ARE cells were treated with the extracts $(100 \mu \mathrm{g} / \mathrm{mL})$ and ARE activities were assayed. SFN, sulforaphane $(5 \mu \mathrm{M})$, is an ARE activator. Brstl, brusatol, is an Nrf2 inhibitor. $N=3$; error bars, mean \pm SEM. Asterisks indicate significant differences in comparison with the control (no treatment). Hashtags for the brusatol-treated conditions indicate significant differences in comparison with their counteracting conditions, in which cells were treated with sample but not with brusatol.

extract may contain diverse substances that work in a combinatorial manner to enhance Nrf2-mediated antioxidation potential and to reduce cancer cell motility. Identification of bioactive substances included in CJ extract and their biological functions awaits further study.

Multiple studies have demonstrated antioxidant activities of CC, CJ, and VD extracts. Several bioactive components from different parts of CJ have been reported: triterpenes in its flowers [33], flavonol glycoside in its leaves [34, 35], and saponins in its seeds [36]. Recently, it was found that the ethanol extract of CJ fruits exhibited a vascular protective effect by endothelial-dependent vasorelaxation [37] and that oleanane triterpenoids isolated from CJ fruits may be beneficial in the treatment of type 2 diabetes and obesity via PTP1B inhibitory activity [38]. Such findings suggest that CJ fruits may have biological effects through the functioning of bioavailable constituents. In addition, Noh and colleagues reported that the methanol extract of the inner shell of CC could protect hepatic cells from oxidative stress through the activation of antioxidant enzymes in vitro and in vivo and that the extract constituents scoparone and scopoletin were identified as potently active compounds [39, 40]. Kim and colleagues reported that the crude extract of VD (squeezed fruit juice) had strong antioxidant activities, reducing oxidative insults in vitro and in vivo, and that the key components involved were anthocyanins and phenolics [41, 42]. 

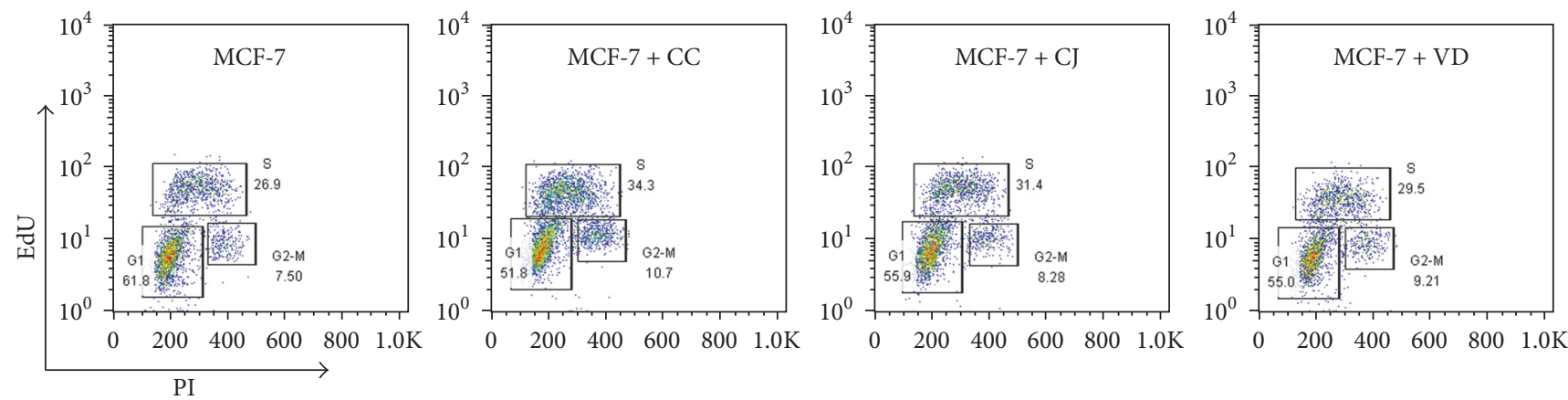

(a)

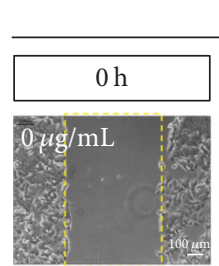

- TPA

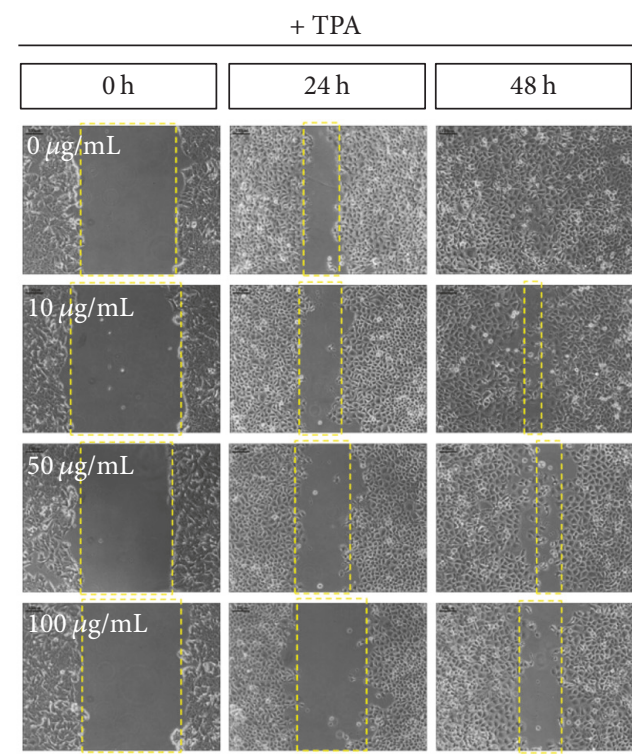

$\left(b_{1}\right)$

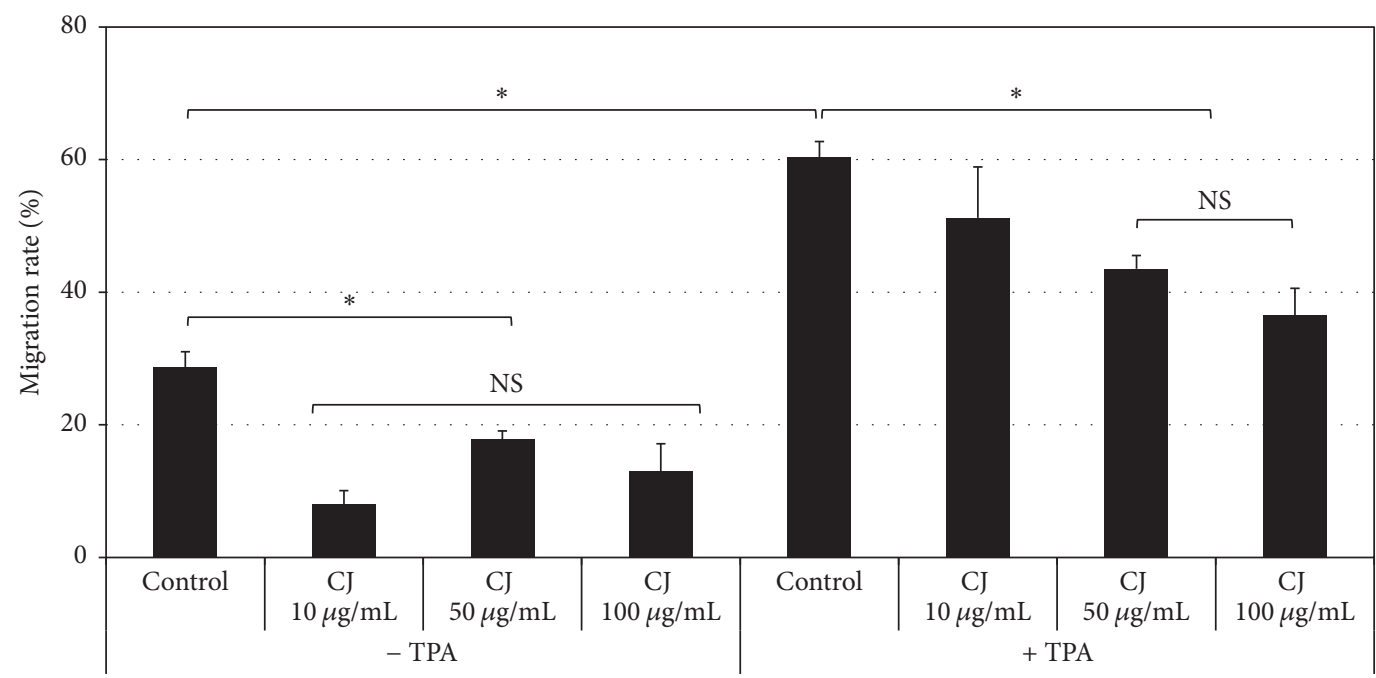

$\left(\mathrm{b}_{2}\right)$

(b)

FIGURE 3: Influence of CJ extract on cell cycle progression and motility of MCF-7 cells. (a) Cells that underwent G1, S, and G2-M phases of cell cycle were analyzed by a thymidine analogue, EdU/PI-based cell sorting after treatment with each extract at a concentration of $50 \mu \mathrm{g} / \mathrm{mL}$ for $48 \mathrm{~h}$. EdU, 5-ethynyl-2'-deoxyuridine. PI, propidium iodide. (b) Cell migration assay. $\left(\mathrm{b}_{1}\right)$ Representative images of cultured cells in the presence of CJ extract at the concentrations of $0,10,50$, and $100 \mu \mathrm{g} / \mathrm{mL}$. The scale bar in a panel of $\left(\mathrm{b}_{1}\right)$ represents $100 \mu \mathrm{m}$, applicable to all panels in $\left(b_{1}\right) .\left(b_{2}\right)$ Quantification of cell migration rate under the designated cultured conditions. $N=3$; error bars, mean \pm SEM. Asterisks indicate significant differences among the conditions. NS, no significant difference. 
In this study, edible plant extracts were evaluated for their antioxidant potential using various in vitro assays. Our findings can be summarized in the form of three main contributions. Firstly, we found that CC, CJ, and VD extracts had strong free radical scavenging and lipid peroxidation inhibitory activities. Secondly, the extracts reduced tBHPinduced ROS levels, which were mediated through the activation of the Nrf2 signaling pathway. Thirdly, CJ extract among the three extracts barely affected cancer cell proliferation but decreased in vitro cancer cell migration. These findings demonstrated the antioxidant capability of CC, CJ, and VD extracts and potent anticancer effect of CJ, which could have implication in development of anticancer functional foods and natural source-derived nutraceuticals for cancer prevention.

\section{Abbreviations}

$\begin{array}{ll}\text { ABTS: } & \text { 3-Ethylbenzothiazoline-6-sulfonic acid } \\ \text { ARE: } & \text { Antioxidant response element } \\ \text { BHT: } & \text { Butylated hydroxytoluene } \\ \text { CC: } & \text { Castanea crenata (leaf) } \\ \text { CJ: } & \text { Camellia japonica (fruit) } \\ \text { DCF: } & \text { Dichlorofluorescein } \\ \text { DCFH-DA: } & \text { 2,7-Dichlorodihydrofluorescein diacetate } \\ \text { DPPH: } & \text { 2,2-Diphenyl-1-picrylhydrazyl } \\ \text { EdU: } & \text { 5-Ethynyl-2'-deoxyuridine } \\ \text { FBS: } & \text { Fetal bovine serum } \\ \text { FRAP: } & \text { Ferric reducing/antioxidant power } \\ \text { HPLC-DAD: } & \text { High-performance liquid } \\ & \text { chromatography-diode array detection } \\ \text { MDA: } & \text { Malondialdehyde } \\ \text { Nrf2: } & \text { Nuclear factor erythroid 2-related factor } 2 \\ \text { PI: } & \text { Propidium iodide } \\ \text { ROS: } & \text { Reactive oxygen species } \\ \text { TBARS: } & \text { Thiobarbituric acid reactive substances } \\ \text { tBHP: } & \text { Tert-butyl hydroperoxide } \\ \text { TPA: } & \text { 12-O-Tetradecanoylphorbol-13-acetate } \\ \text { VD: } & \text { Viburnum dilatatum (leaf). } \\ & \end{array}$

\section{Conflicts of Interest}

The authors declare that there are no conflicts of interest regarding the publication of this article.

\section{Acknowledgments}

This work was supported by the Korea Institute of Planning and Evaluation for Technology in Food, Agriculture, Forestry and Fisheries (IPET) through the High Value-Added Food Technology Development Program, funded by the Ministry of Agriculture, Food and Rural Affairs (MAFRA), Republic of Korea (Grant no. 116026-03-2-HD020).

\section{References}

[1] B. M. Hybertson, B. Gao, S. K. Bose, and J. M. McCord, "Oxidative stress in health and disease: the therapeutic potential of Nrf2 activation," Molecular Aspects of Medicine, vol. 32, no. 4-6, pp. 234-246, 2011.
[2] R. K. Gupta, A. K. Patel, N. Shah et al., "Oxidative stress and antioxidants in disease and cancer: a review," Asian Pacific Journal of Cancer Prevention, vol. 15, no. 11, pp. 4405-4409, 2014.

[3] T. Finkel and N. J. Holbrook, "Oxidants, oxidative stress and the biology of ageing," Nature, vol. 408, no. 6809, pp. 239-247, 2000.

[4] B. Halliwell, R. Aeschbach, J. Löliger, and O. I. Aruoma, "The characterization of antioxidants," Food and Chemical Toxicology, vol. 33, no. 7, pp. 601-617, 1995.

[5] C. I. Abuajah, A. C. Ogbonna, and C. M. Osuji, "Functional components and medicinal properties of food: a review," Journal of Food Science and Technology, vol. 52, no. 5, pp. 2522-2529, 2015.

[6] S. Nam, H. W. Jang, and T. Shibamoto, "Antioxidant activities of extracts from teas prepared from medicinal plants, morus alba L., camellia sinensis L., and cudrania tricuspidata, and their volatile components," Journal of Agricultural and Food Chemistry, vol. 60, no. 36, pp. 9097-9105, 2012.

[7] F. Virgili and M. Marino, "Regulation of cellular signals from nutritional molecules: a specific role for phytochemicals, beyond antioxidant activity," Free Radical Biology \& Medicine, vol. 45, no. 9, pp. 1205-1216, 2008.

[8] Y.-J. Zhang, R.-Y. Gan, S. Li et al., "Antioxidant phytochemicals for the prevention and treatment of chronic diseases," Molecules, vol. 20, no. 12, pp. 21138-21156, 2015.

[9] Z. Y. Su, L. Shu, T. O. Khor, J. H. Lee, F. Fuentes, and A. N. T. Kong, "A perspective on dietary phytochemicals and cancer chemoprevention: oxidative stress, Nrf2, and epigenomics," Topics in Current Chemistry, vol. 329, pp. 133-162, 2013.

[10] Y. Surh, "Cancer chemoprevention with dietary phytochemicals," Nature Reviews Cancer, vol. 3, no. 10, pp. 768-780, 2003.

[11] K. Ahn, "The worldwide trend of using botanical drugs and strategies for developing global drugs," BMB Reports, vol. 50, no. 3, pp. 111-116, 2017.

[12] F. Ariffin, S. Heong Chew, K. Bhupinder, A. A. Karim, and N. Huda, "Antioxidant capacity and phenolic composition of fermented Centella asiatica herbal teas," Journal of the Science of Food and Agriculture, vol. 91, no. 15, pp. 2731-2739, 2011.

[13] Y. Lee, J. Oh, H. Lee, N. K. Lee, D.-Y. Jeong, and Y.-S. Jeong, "Lactic acid bacteria-mediated fermentation of Cudrania tricuspidata leaf extract improves its antioxidative activity, osteogenic effects, and anti-adipogenic effects," Biotechnology and Bioprocess Engineering, vol. 20, no. 5, pp. 861-870, 2015.

[14] J. Oh, S. B. Jeon, Y. Lee et al., "Fermented red ginseng extract inhibits cancer cell proliferation and viability," Journal of Medicinal Food, vol. 18, no. 4, pp. 421-428, 2015.

[15] Y. Lee, J. Oh, and Y.-S. Jeong, " Lactobacillus plantarummediated conversion of flavonoid glycosides into flavonols, quercetin, and kaempferol in Cudrania tricuspidata leaves," Food Science and Biotechnology, vol. 24, no. 5, pp. 1817-1821, 2015.

[16] I. F. F. Benzie and J. J. Strain, "The ferric reducing ability of plasma (FRAP) as a measure of 'antioxidant power': the FRAP assay," Analytical Biochemistry, vol. 239, no. 1, pp. 70-76, 1996.

[17] H. J. Kim, J.-Y. Seo, H.-J. Suh, S. S. Lim, and J.-S. Kim, "Antioxidant activities of licorice-derived prenylflavonoids," Nutrition Research and Practice, vol. 6, no. 6, pp. 491-498, 2012.

[18] Y. Woo, J. Oh, and J. Kim, "Suppression of Nrf2 Activity by Chestnut Leaf Extract Increases Chemosensitivity of Breast Cancer Stem Cells to Paclitaxel," Nutrients, vol. 9, no. 7, p. 760, 2017.

[19] H. Wang and J. A. Joseph, "Quantifying cellular oxidative stress by dichlorofluorescein assay using microplate reader," Free Radical Biology \& Medicine, vol. 27, no. 5-6, pp. 612-616, 1999. 
[20] B. R. Kim, R. Hu, Y. S. Keum et al., "Effects of of glutathione on antioxidant response element-mediated gene expression and apoptosis elicited by sulforaphane," Cancer Research, vol. 63, no. 21, pp. 7520-7525, 2003.

[21] D. Ren, N. F. Villeneuve, T. Jiang et al., "Brusatol enhances the efficacy of chemotherapy by inhibiting the Nrf2-mediated defense mechanism," Proceedings of the National Acadamy of Sciences of the United States of America, vol. 108, no. 4, pp. 14331438, 2011.

[22] C. C. Liang, A. Y. Park, and J. L. Guan, "In vitro scratch assay: a convenient and inexpensive method for analysis of cell migration in vitro," Nature Protocols, vol. 2, no. 2, pp. 329-333, 2007.

[23] H. He, S. Li, H. Chen et al., "12-O-tetradecanoylphorbol13-acetate promotes breast cancer cell motility by increasing S100A14 Level in a Kruppel-like transcription factor 4 (KLF4)dependent manner," The Journal of Biological Chemistry, vol. 289, no. 13, pp. 9089-9099, 2014.

[24] J. E. De Vente, C. A. Kukoly, W. O. Bryant et al., "Phorbol esters induce death in MCF-7 breast cancer cells with altered expression of protein kinase C isoforms: Role for p53-independent induction of gadd45 in initiating death," The Journal of Clinical Investigation, vol. 96, no. 4, pp. 1874-1886, 1995.

[25] N. MacDonald, "Natural compounds in cancer therapy," Journal of Palliative Care, vol. 18, no. 4, pp. 312-313, 2002.

[26] G. M. Cragg, M. R. Boyd, J. H. Cardellina 2nd., D. J. Newman, K. M. Snader, and T. G. McCloud, "Ethnobotany and drug discovery: the experience of the US National Cancer Institute.," CIBA Foundation Symposia, vol. 185, pp. 178-190, 1994.

[27] J. W. Finley, A.-N. Kong, K. J. Hintze, E. H. Jeffery, L. L. Ji, and X. G. Lei, "Antioxidants in foods: state of the science important to the food industry," Journal of Agricultural and Food Chemistry, vol. 59, no. 13, pp. 6837-6846, 2011.

[28] Y. Huang, W. Li, Z.-Y. Su, and A.-N. T. Kong, "The complexity of the Nrf2 pathway: beyond the antioxidant response," The Journal of Nutritional Biochemistry, vol. 26, no. 12, pp. 1401-1413, 2015.

[29] W.-L. Lee, J.-Y. Huang, and L.-F. Shyur, "Phytoagents for cancer management: regulation of nucleic acid oxidation, ROS, and related mechanisms," Oxidative Medicine and Cellular Longevity, vol. 2013, Article ID 925804, 22 pages, 2013.

[30] N. M. Reddy, S. R. Kleeberger, J. H. Bream et al., "Genetic disruption of the Nrf2 compromises cell-cycle progression by impairing GSH-induced redox signaling," Oncogene, vol. 27, no. 44, pp. 5821-5832, 2008.

[31] M. C. Jaramillo and D. D. Zhang, "The emerging role of the Nrf2-Keap1 signaling pathway in cancer," Genes \& Development, vol. 27, no. 20, pp. 2179-2191, 2013.

[32] C. Zhang, H.-J. Wang, Q.-C. Bao et al., "NRF2 promotes breast cancer cell proliferation and metastasis by increasing RhoA/ROCK pathway signal transduction," Oncotarget, vol. 7, no. 45, pp. 73593-73606, 2016.

[33] M. J. I. Piao, E. S. O. Yoo, Y. S. A. Koh et al., "Antioxidant effects of the ethanol extract from flower of Camellia japonica via scavenging of reactive oxygen species and induction of antioxidant enzymes," International Journal of Molecular Sciences, vol. 12, no. 4, pp. 2618-2630, 2011.

[34] K.-I. Onodera, K. Hanashiro, and T. Yasumoto, "Camellianoside, a novel antioxidant glycoside from the leaves of Camellia japonica," Bioscience, Biotechnology, and Biochemistry, vol. 70, no. 8, pp. 1995-1998, 2006.
[35] T. Mizutani and H. Masaki, "Anti-photoaging capability of antioxidant extract from Camellia japonica leaf," Experimental Dermatology, vol. 23, supplement 1, pp. 23-26, 2014.

[36] M. Yoshikawa, E. Harada, T. Murakami, H. Matsuda, J. Yamahara, and N. Murakami, "Camelliasaponins B1,B2,C1 and C2, new type inhibitors of ethanol absorption in rats from the seeds of camellia japonica l," Chemical \& Pharmaceutical Bulletin, vol. 42, no. 3, pp. 742-744, 1994.

[37] S. H. Park, B. S. Shim, J. S. Yoon et al., "Vascular protective effect of an ethanol extract of Camellia japonica fruit: endotheliumdependent relaxation of coronary artery and reduction of smooth muscle cell migration," Oxidative Medicine and Cellular Longevity, vol. 2016, Article ID 6309565, 9 pages, 2016.

[38] M. N. Uddin, G. Sharma, J.-L. Yang et al., "Oleanane triterpenes as protein tyrosine phosphatase $1 \mathrm{~B}$ (PTP1B) inhibitors from Camellia japonica," Phytochemistry, vol. 103, pp. 99-106, 2014.

[39] J.-R. Noh, G.-T. Gang, Y.-H. Kim et al., "Antioxidant effects of the chestnut (Castanea crenata) inner shell extract in t-BHPtreated HepG2 cells, and CCl4- and high-fat diet-treated mice," Food and Chemical Toxicology, vol. 48, no. 11, pp. 3177-3183, 2010.

[40] J.-R. Noh, Y.-H. Kim, G.-T. Gang et al., "Hepatoprotective effects of chestnut (Castanea crenata) inner shell extract against chronic ethanol-induced oxidative stress in C57BL/6 mice," Food and Chemical Toxicology, vol. 49, no. 7, pp. 1537-1543, 2011.

[41] M.-Y. Kim, K. Iwai, A. Onodera, and H. Matsue, "Identification and antiradical properties of anthocyanins in fruits of Viburnum dilatatum Thunb.," Journal of Agricultural and Food Chemistry, vol. 51, no. 21, pp. 6173-6177, 2003.

[42] K. Iwai, M.-Y. Kim, A. Onodera, and H. Matsue, "Physiological effects and active ingredients of Viburnum dilatatum Thunb fruits on oxidative stress," BioFactors, vol. 21, no. 1-4, pp. 273275,2004 . 

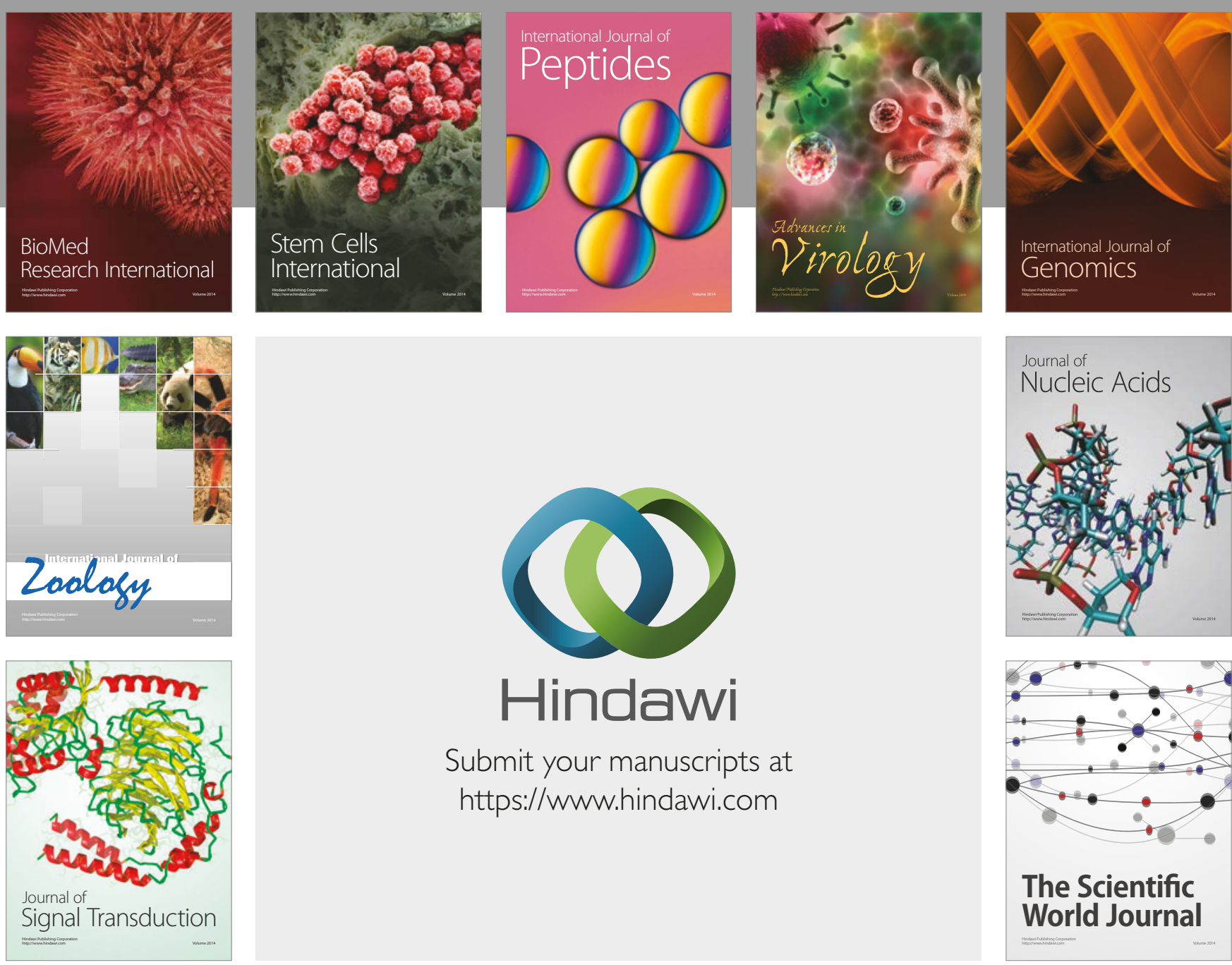

Submit your manuscripts at

https://www.hindawi.com
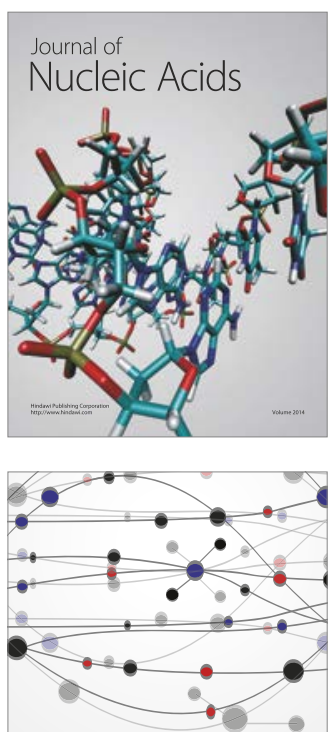

The Scientific World Journal

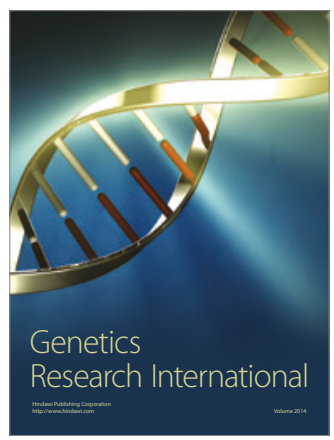

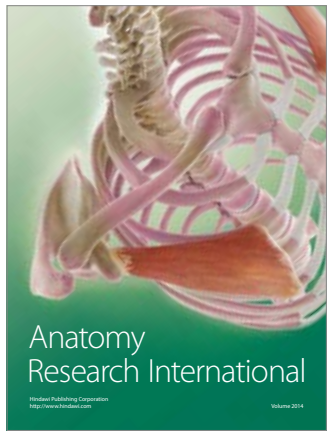

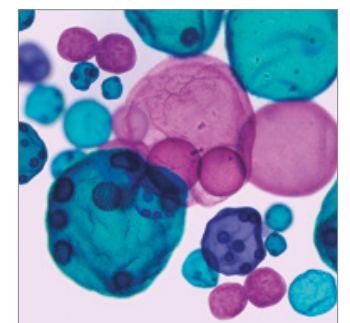

International Journal of Microbiology
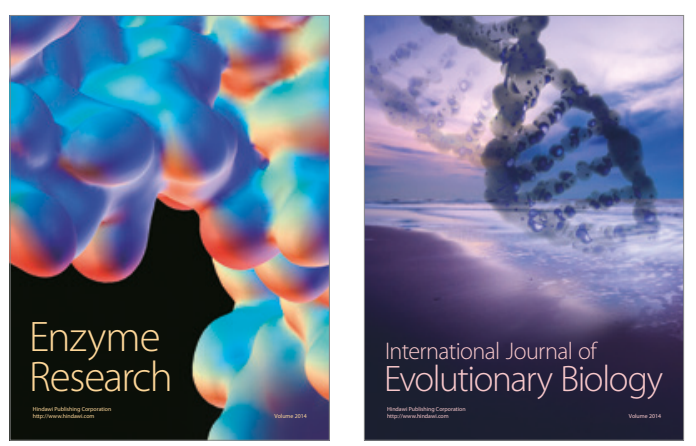
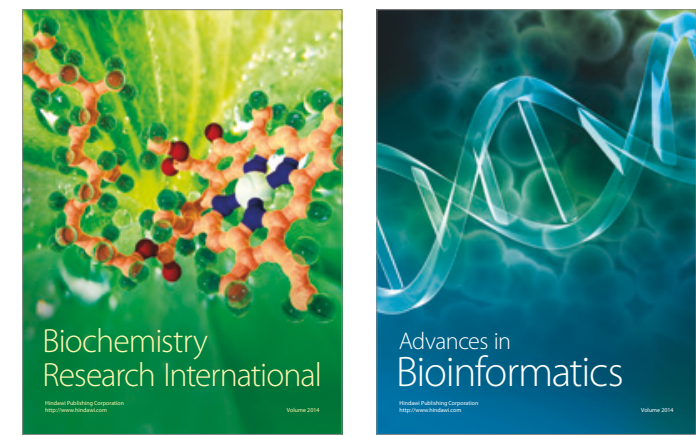

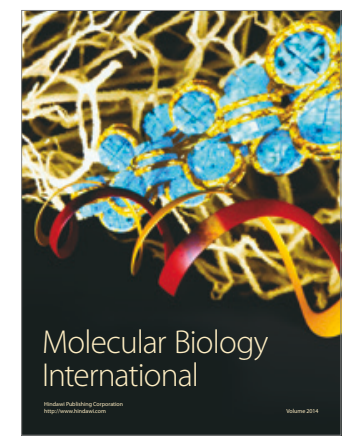

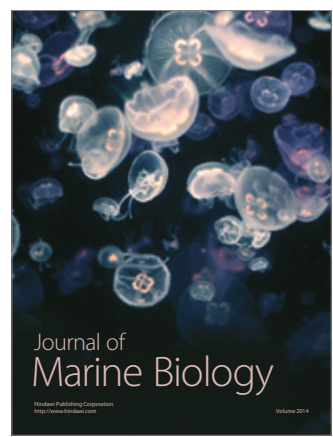

